\title{
FTIR Characterization of the Development of Antimicrobial Catheter Coatings Loaded with Fluoroquinolones
}

\author{
Dorota Kowalczuk $(\mathbb{D}$ \\ Chair and Department of Medicinal Chemistry, Faculty of Pharmacy, The Medical University of Lublin, \\ 20-090 Lublin, Poland; dorota.kowalczuk@umlub.pl; Tel.: +48-81-448-7380
}

Received: 3 August 2020; Accepted: 22 August 2020; Published: 24 August 2020

\begin{abstract}
The purpose of this paper was to present the development of antimicrobial coatings for different urinary catheters. Antimicrobial catheter coatings were prepared by immobilizing fluoroquinolones either with the use of linkers (covalent binding) or by activating the polymer matrix with iodine/bromine (noncovalent binding). The possibility of the deposition of antimicrobial agent(s) following bromine activation on latex, polyurethane, and silicone was evaluated. Fourier transform infrared spectroscopy (FTIR), used to monitor the changes in the catheter's molecular structure occurring over the course of its multi-stage modification, confirmed the presence of fluoroquinolones in the catheter matrix as well as site-specific reactions. The amounts of drugs embedded in the catheter matrix were determined by the HPLC method. Stability of the drug binding was checked by examining the drug release. The new antimicrobial coatings obtained with the participation of fluoroquinolone antibiotics have the potential to protect the patient against infections during catheterization.
\end{abstract}

Keywords: antimicrobial coatings; urinary catheters; catheter-associated urinary tract infections; FTIR; fluoroquinolones

\section{Introduction}

Scientists have long been searching for ideal biomaterials (i.e., those made up of biocompatible, antimicrobial, and antifouling materials) that would be capable of inhibiting bacterial adhesion, thereby preventing infections in the course of urinary catheterization.

The surface properties of materials such as morphology, functionality, surface charge density, interactions, hydrophilicity or hydrophobicity play a vital role in bacterial adhesion. With regard to the surface properties, the modifications are mainly accomplished by applying the following strategies: functionalization, coating, impregnation of the active molecule, and blending. The former two cause the development of bacteriostatic surfaces, whereas molecule impregnation and blending result in the development of bactericidal surfaces [1].

It appears that modification of the surface structure of the urinary catheter could reduce the incidence of urinary tract infections. Coating the catheter surfaces with a thin layer of a suitable material is apparently the most universal method aimed at developing antifouling and antibacterial properties. Thus far, thin films based on silicone, polytetrafluoroethylene, hydrogels, and other antifouling/antimicrobial materials, often containing silver or an alternative metal as well as other antimicrobials, have been proposed [1-3].

Scientific studies indicate that bacterial adhesion can be reduced by coating the catheters with titanium dioxide [4], a titanium oxide-silver composite [5], silver particles/silver nanoparticles [6], or impregnating the catheter with nitric oxide [7]. 
Sterility and prevention of bacterial adhesion (prevention of catheter-associated bacteriuria) can be achieved by incorporating into the catheter antiseptics such as triclosan, chlorhexidine) $[8,9]$, antibiotics/chemotherapeutic agents including fluoroquinolones [10-12], or other active substance/ polymer $[12,13]$.

Fourier transform infrared spectroscopy is the most commonly used technique to assess the surface changes of biomaterials that occur during their modification [14,15].

Since the research into the immobilization of active substances in solid biomaterials requires further investigation [16], this paper focused on investigating various ways of the immobilization of fluoroquinolone antibacterial substances and its aim was to present the development of antimicrobial coatings of different urinary catheters as well as the FTIR assessment of changes in the molecular structure of the catheter material during its multi-stage modification. This paper presents the formation and characterization of the new antimicrobial coatings, obtained with the participation of fluoroquinolone antibiotics in an uncomplicated way, which can protect urinary catheters against bacterial infections. As indicated by the literature data, modifications of the catheter are vital to ensure the patient's safety during urinary catheterization.

\section{Materials and Methods}

Sparfloxacin (SPA) and ciprofloxacin hydrochloride monohydrate (CIP) were purchased from Sigma-Aldrich. All reagents and chemicals used for the modification process of catheters were purchased from Sigma-Aldrich Co. (chitosan, CHT; glutaraldehyde GLU; adipic acid dihydrazide, ADH) or Avantor Performance Materials Poland S.A., Gliwice, Poland (iodine, bromine, methanol, acetonitrile). The Foley catheters were made of a natural latex; siliconized, silicone, polyurethane, and hydrogel-coated latex were obtained from a local medical supplier (Skamex, Łódź, Poland).

\subsection{Preparation of Sparfloxacin-Treated Catheter Samples (SPA-M1 Method)}

The siliconized latex catheters were subjected to the modification process using the selected patented procedures [17], adapted for this research.

Small samples of $0.5 \mathrm{~cm}$-long catheters (average weight about $0.09 \mathrm{~g}$ ) were coated with chitosan, then treated with glutaraldehyde and finally coupled with sparfloxacin in an organic medium. With regard to the biotoxic effect of glutaraldehyde, the non-crosslinked (trapped) glutaraldehyde was removed by repeatedly rinsing the crosslinked chitosan catheter with distilled water. Immobilization of SPA on the crosslinked chitosan-coated catheter surface was performed in the SPA solutions prepared in acetonitrile at the concentration of $0.1,0.5,1.0$, and $2.0 \mathrm{mg} / \mathrm{mL}$. The resulting catheter samples were rinsed with water, dried at $50{ }^{\circ} \mathrm{C}$ mand subjected to ATR (Attenuated Total Reflectance)-FTIR analysis.

\subsection{Preparation of Sparfloxacin-Treated Catheter Samples (SPA-M2 and SPA-M3 Methods)}

The hydrogel catheters (also polyurethane and silicone catheters in the case of the SPA-M3 method) were cut into $0.5 \mathrm{~cm}$-long fragments (average weight about $0.11 \mathrm{~g}$ ) and activated with the $1 \%$ methanol- $\mathrm{NaHCO}_{3}$ iodine solution (SPA-M2 method) or $0.1-1 \%$ methanolic bromine solution (SPA-M3 method) for $1 \mathrm{~h}$ under gentle stirring at $40{ }^{\circ} \mathrm{C}$. Next, the samples were removed, rinsed with distilled water, and dried. In the next stage, the samples were placed in Eppendorf tubes, immersed in $1 \mathrm{~mL}$ of SPA solution $(0.1,0.5,1.0$, and $2.0 \mathrm{mg} / \mathrm{mL})$ and incubated in closed tubes for $12 \mathrm{~h}$ at $50^{\circ} \mathrm{C}$ with stirring at $150 \mathrm{rpm}$. Then, the catheters were removed, rinsed with water, and left to dry.

\subsection{Preparation of Ciprofloxacin-Treated Catheter Samples (CIP-M1 Method)}

The siliconized latex catheters were subjected to the modification process using the selected patented procedures [17], adapted for this research.

The small samples of $0.5 \mathrm{~cm}$-long catheters (average weight about $0.09 \mathrm{~g}$ ) were coated with chitosan, then, sequentially treated with the $5 \%$ solution of glutaraldehyde and $5 \%$ solution of adipic acid dihydrazide and finally coupled with ciprofloxacin in an organic medium. With regard to the biotoxic 
effect of glutaraldehyde, the trapped glutaraldehyde was removed by repeatedly rinsing the crosslinked chitosan catheter with distilled water. Immobilization of CIP on the activated, chitosan-coated catheter surface was performed in the CIP solutions prepared in methanol at the concentrations of $0.1,0.5,1.0$, and $2.5 \mathrm{mg} / \mathrm{mL}$. The resulting catheter samples were rinsed with water, dried at $50{ }^{\circ} \mathrm{C}$, and subjected to ATR-FTIR analysis.

\subsection{FTIR Characterization}

FTIR in transmittance mode was used to characterize the presence of specific chemical groups.

In the tested catheter samples. FTIR measurements were carried out on a Nicolet 6700 spectrometer (Thermo Fisher Scientific Inc., Warsaw, Poland) equipped with a deuterated triglycine sulfate detector (DTGS/KBr) and a versatile attenuated total reflectance (ATR) sampling accessory with a diamond crystal plate. The spectra were recorded in the spectral range of $4000-600 \mathrm{~cm}^{-1}$ at $4 \mathrm{~cm}^{-1}$ spectral resolution and 32 sample/background scans using OMNIC 8.1 computer software (Thermo Fisher Scientific Inc., Waltham, MA USA). The modified catheters were recorded and compared with the unmodified ones.

\section{Results}

The presented FTIR-ATR assessments show the effects of the functionalization of various types of urological catheters using selected chemotherapeutics (i.e., sparfloxacin and ciprofloxacin). With the use of the FTIR method, sparfloxacin was proven to be a particularly good choice to demonstrate the presence of this drug in the modified polymer matrix due to the unique absorption bands of the amine group in the range of $4000-3000 \mathrm{~cm}^{-1}$. In addition, fluoroquinoline antibiotics showed a broad spectrum of antibacterial activity and effectively protected modified matrices against biofilm formation, which ensures the patient's safety during catherization.

\subsection{Analysis of the SPA Modified Catheter with the Use of the SPA-M1 Method (CHT-Linker-SPA)}

The FTIR spectrum of the siliconized latex catheter (Figure 1A) shows the absorption bands for silicone and latex. The peaks in the range of 1020 to $1260 \mathrm{~cm}^{-1}$ belong to $\mathrm{Si}-\mathrm{O}-\mathrm{Si}$ bonds of silicone with the peak at about $1100 \mathrm{~cm}^{-1}$ belonging to the $\mathrm{C}-\mathrm{O}-\mathrm{C}$ bonds of the latex, probably the polyacrylate latex, which also showed absorption peaks at about $3300 \mathrm{~cm}^{-1}$ as well as at $3000-2850 \mathrm{~cm}^{-1}$ and $1735 \mathrm{~cm}^{-1}$, that are the result of the stretching vibrations of $\mathrm{O}-\mathrm{H}, \mathrm{C}-\mathrm{H}$, and $\mathrm{C}=\mathrm{O}$ bonds, respectively. Furthermore, the absorption bands at $1480-1380 \mathrm{~cm}^{-1}$ can be attributed to the bending vibrations of the $\mathrm{O}-\mathrm{H}$ and C-H bonds [18].

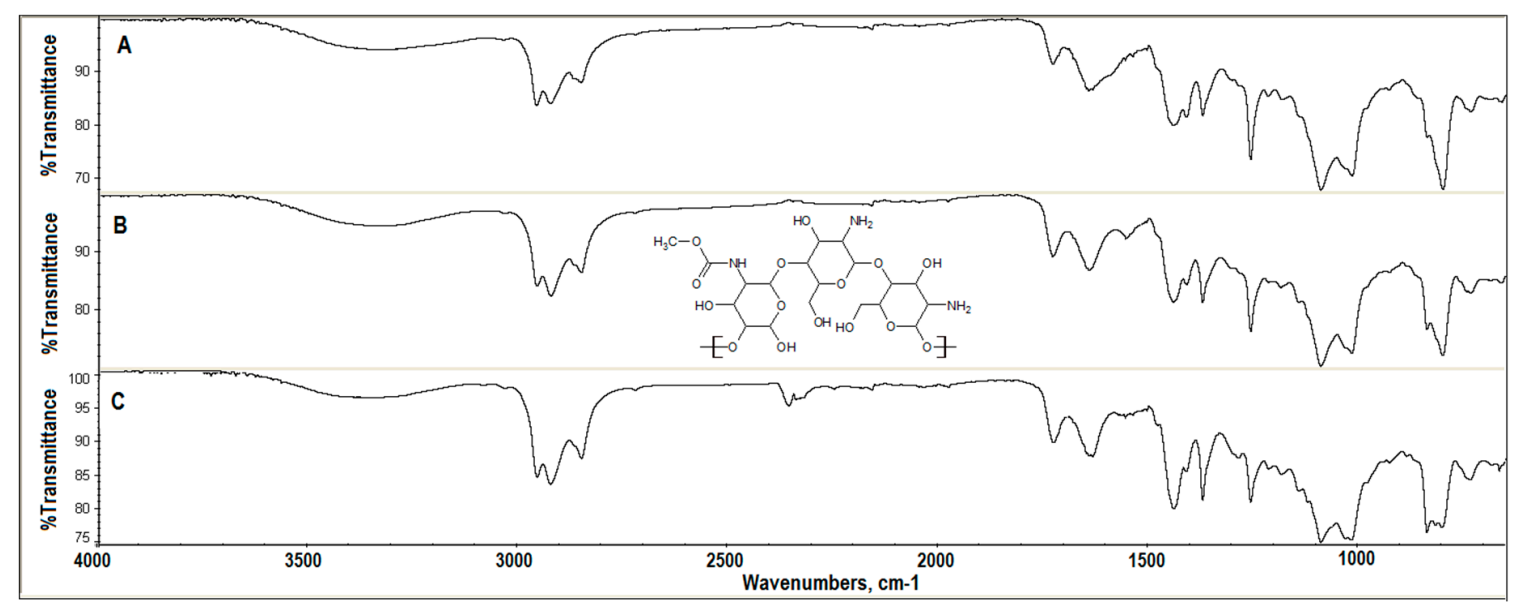

Figure 1. FTIR spectra of the siliconized latex catheter recorded during a three-stage modification using SPA-M1 method: the untreated catheter (A), CHT-treated and GLU-activated catheter (B), SPA-treated catheter $(\mathbf{C})$. 
Comparing curve B with curve A, at $3380 \mathrm{~cm}^{-1}$ there was no clear band related to the free amine group in the molecule of natural chitosan. A comparison of these curves showed an increased intensity in the peaks of the $\mathrm{C}-\mathrm{H}$ stretching at $3000-2850 \mathrm{~cm}^{-1}$ and the carbonyl stretching $(\mathrm{C}=\mathrm{O})$ at $1735 \mathrm{~cm}^{-1}$. Furthermore, two new absorption bands at $1644 \mathrm{~cm}^{-1}$ and at about $1551 \mathrm{~cm}^{-1}$ were observed in the modified chitosan (CHT-treated and GLU-activated catheter). These effects can be related to the interactions between chitosan and glutaraldehyde as a linker. The clear peak at $1644 \mathrm{~cm}^{-1}$ can be associated with the presence of the stretching vibrations of $\mathrm{N}=\mathrm{C}$ bonds. The second peak at $1551 \mathrm{~cm}^{-1}$ can be attributed to the stretching vibrations of $C=C$ bonds. The literature [19] provided evidence for the formation of the double imine bond $(\mathrm{N}=\mathrm{C})$ and the ethylenic double bond $(\mathrm{C}=\mathrm{C})$ in the chitosan-glutaraldehyde interactions, which depend on the $\mathrm{pH}$ value of the reaction medium and the GLU concentration [20]. In the process, crosslinking chains are formed [20,21].

It is apparent that curve C (spectrum of CHT-linker-SPA) was more intensified than curve B. The shape changes of the bands and the new peaks, typical of the SPA molecule [16] at about $1630 \mathrm{~cm}^{-1}$, $1520-1550 \mathrm{~cm}^{-1}, 1430 \mathrm{~cm}^{-1}, 1290 \mathrm{~cm}^{-1}$, and $850-800 \mathrm{~cm}^{-1}$ and attributed to the stretching and bending vibrations, may be indicative of the presence of SPA in the modified catheter. The absence of peaks for the $\mathrm{N}-\mathrm{H}$ stretching bonds, a change in the shape of the imine peak, and a shift of this band to a lower frequency (from 1644 to $1630 \mathrm{~cm}^{-1}$ ) may also suggest the formation of the $\mathrm{C}=\mathrm{N}$ bond between SPA and the cross-linked chitosan (Table 1).

Table 1. Summary of FTIR analysis of the SPA-modified catheter following SPA-M1 method.

\begin{tabular}{cc}
\hline Prominent Peaks of SPA & Prominent Peaks of SPA-Modified Catheter \\
\hline$v(\mathrm{~N}-\mathrm{H}): 3460 \mathrm{~cm}^{-1}$ and $3336 \mathrm{~cm}^{-1}$ & $v(\mathrm{~N}-\mathrm{H}):$ absence \\
$v(\mathrm{C}=\mathrm{O}): 1639 \mathrm{~cm}^{-1}$ & $v(\mathrm{C}=\mathrm{N}): \sim 1630 \mathrm{~cm}^{-1}$ \\
$v(\mathrm{C}=\mathrm{C}$ in $\mathrm{Ar})$ with $\delta(\mathrm{N}-\mathrm{H}): 1585-1495 \mathrm{~cm}^{-1}$ & $v(\mathrm{C}=\mathrm{C}$ in $\mathrm{Ar}): \sim 1520-1550 \mathrm{~cm}^{-1}$ \\
$\delta(\mathrm{C}-\mathrm{H}$ in $-\mathrm{CH} 2-): 1435 \mathrm{~cm}^{-1}$ & $\delta(\mathrm{C}-\mathrm{H}$ in $-\mathrm{CH} 2-): \sim 1430 \mathrm{~cm}^{-1}$, \\
$v(\mathrm{C}-\mathrm{O}$ in $\mathrm{COOH}): 1290 \mathrm{~cm}^{-1}$ & $v(\mathrm{C}-\mathrm{O}$ in $\mathrm{COOH}): \sim 1290 \mathrm{~cm}^{-1}$ \\
\hline
\end{tabular}

Moreover, the binding of SPA to the cross-linked chitosan due to the Michael-type reaction may also be taken into consideration [21]. Probable covalent SPA binding sites are shown in Scheme 1.

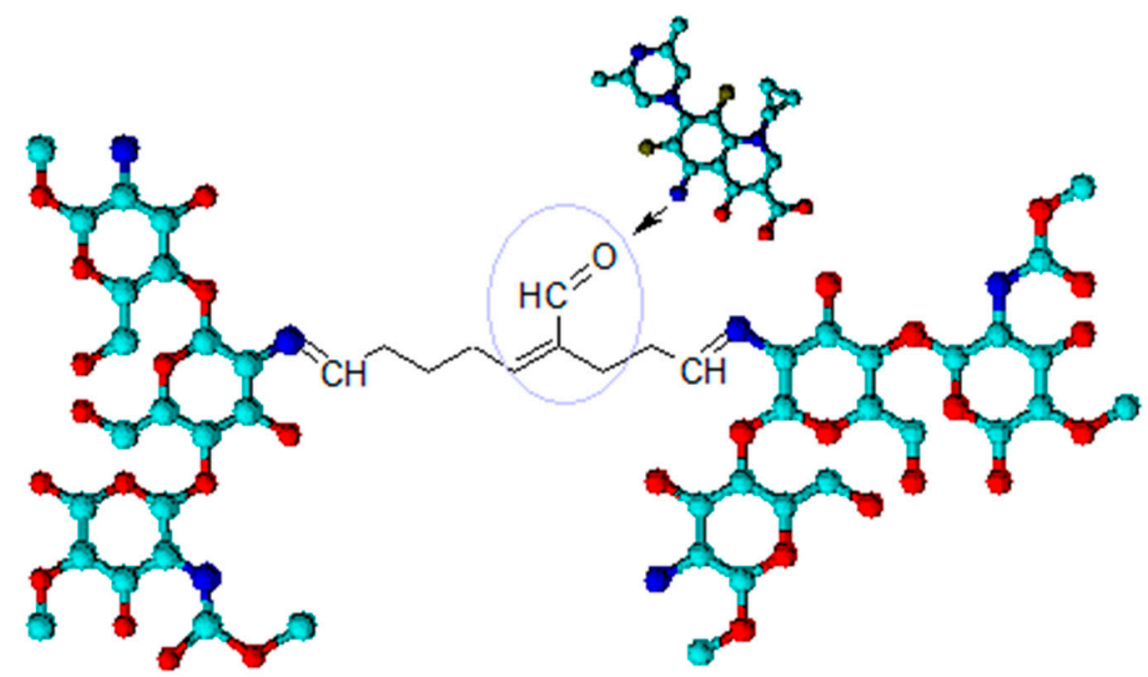

Scheme 1. Probable covalent SPA binding with the crosslinking chitosan.

\subsection{Analysis of the SPA-Modified Catheter with the Use of SPA-M2 Method (Iodine-SPA)}

A hydrogel, which is a cross-linked macromolecular polymer that absorbs relatively large volumes of a liquid, is a material frequently used for coating urinary catheters. The most commonly used hydrogel is made of poly(2-hydroxyethyl methacrylate) [22]. 
The FTIR spectrum of the hydrogel catheter (Figure 2A) showed a wide absorption band of $\mathrm{O}-\mathrm{H}$ stretching vibrations at about $3300-3500 \mathrm{~cm}^{-1}$, peaks corresponding to the $\mathrm{C}-\mathrm{H}$ stretching vibrations at $3000-2850 \mathrm{~cm}^{-1}$, the $\mathrm{C}=\mathrm{O}$ stretching vibrations at $1710 \mathrm{~cm}^{-1}$, the $\mathrm{C}-\mathrm{O}-\mathrm{C}$ stretching vibrations at about $1100 \mathrm{~cm}^{-1}$ as well as the bending vibrations of the $\mathrm{C}-\mathrm{H}$ bonds in the region $1360-1480 \mathrm{~cm}^{-1}$ [23] The absorption bands indicate the presence of similar functional moieties, as in the case of the siliconized latex catheter (Figure 1A).

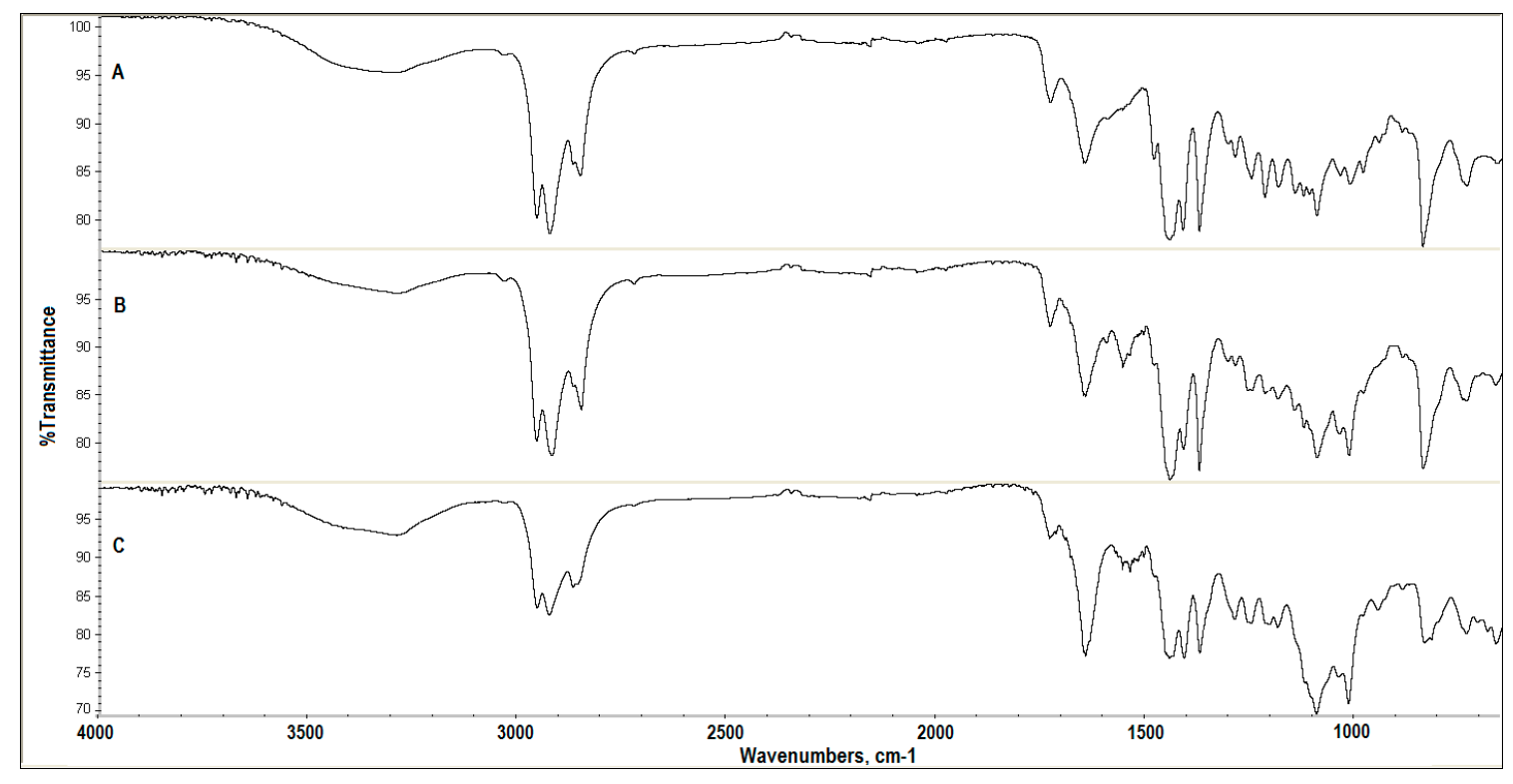

Figure 2. FTIR spectra of the hydrogel catheter recorded during a two-stage modification using the SPA-M2 method: the untreated hydrogel catheter (A), the iodine-activated catheter (B), SPA-treated catheter $(\mathbf{C})$.

The spectra recorded after the second and third stage of modification (Figure 2A,B) were similar to those presented earlier [16]. However, the FTIR spectra demonstrated here were obtained by spectroscopic analysis where the latex-based catheter was coated with a hydrogel layer, treated with iodine in an organic-aqueous environment, and then with SPA as an antibacterial agent. The characteristic absorption bands appearing as new peaks in the FTIR spectrum of the iodine-activated and SPA-treated catheter (Figure 2C) clearly indicate the presence of SPA. The intensive absorption bands corresponding to the asymmetrical and symmetrical stretching vibrations of the $\mathrm{N}-\mathrm{H}$ bonds of SPA overlapped with the $\mathrm{O}-\mathrm{H}$ stretching occurred at $3500-3295 \mathrm{~cm}^{-1}$. Comparing curve $\mathrm{C}$ with curve $\mathrm{B}$, the absorption peak at $1639 \mathrm{~cm}^{-1}$ (the $\mathrm{C}=\mathrm{O}$ stretching in the 4-quinolone ring of the SPA molecule) became more intensified and slightly shifted to a lower frequency (from 1647 to $1639 \mathrm{~cm}^{-1}$ ). The peaks at $1585-1500 \mathrm{~cm}^{-1}$ resulted from the $\mathrm{C}=\mathrm{C}$ stretching vibrations of the aromatic ring while the peak at $1291 \mathrm{~cm}^{-1}$ can be assigned to the $\mathrm{C}-\mathrm{O}$ bond vibration of the carboxyl group (Table 2).

Table 2. Summary of the FTIR analysis of SPA-modified catheter following the SPA-M2 method.

\begin{tabular}{cc}
\hline Prominent Peaks of SPA & Prominent Peaks of SPA-Modified Catheter \\
\hline$v(\mathrm{~N}-\mathrm{H}): 3460 \mathrm{~cm}^{-1}$ and $3336 \mathrm{~cm}^{-1}$ & $v(\mathrm{~N}-\mathrm{H}): \sim 3500-3295 \mathrm{~cm}^{-1}$ \\
$v(\mathrm{C}=\mathrm{O}): 1639 \mathrm{~cm}^{-1}$ & $v(\mathrm{C}=\mathrm{O}): \sim 1639 \mathrm{~cm}^{-1}$ \\
$v(\mathrm{C}=\mathrm{C}$ in $\mathrm{Ar})$ with $\delta(\mathrm{N}-\mathrm{H}): 1585-1495 \mathrm{~cm}^{-1}$ & $v(\mathrm{C}=\mathrm{C}$ in $\mathrm{Ar})$ with $\delta(\mathrm{N}-\mathrm{H}): \sim 1585-1500 \mathrm{~cm}^{-1}$ \\
$\delta(\mathrm{C}-\mathrm{H}$ in $-\mathrm{CH} 2-): 1435 \mathrm{~cm}^{-1}$ & $\delta(\mathrm{C}-\mathrm{H}$ in $-\mathrm{CH} 2-): \sim 1436 \mathrm{~cm}^{-1}$ \\
$v(\mathrm{C}-\mathrm{O}$ in $\mathrm{COOH}): 1290 \mathrm{~cm}^{-1}$ & $v(\mathrm{C}-\mathrm{O}$ in $\mathrm{COOH}): \sim 1291 \mathrm{~cm}^{-1}$ \\
\hline
\end{tabular}




\subsection{Analysis of the SPA Modified Catheter with the Use of SPA-M3 Method (Bromine-SPA)}

In the case of functionalization of the hydrogel latex catheter with bromine as an activator and SPA as an antibacterial agent, the presence of SPA was even more pronounced (Figure 3).

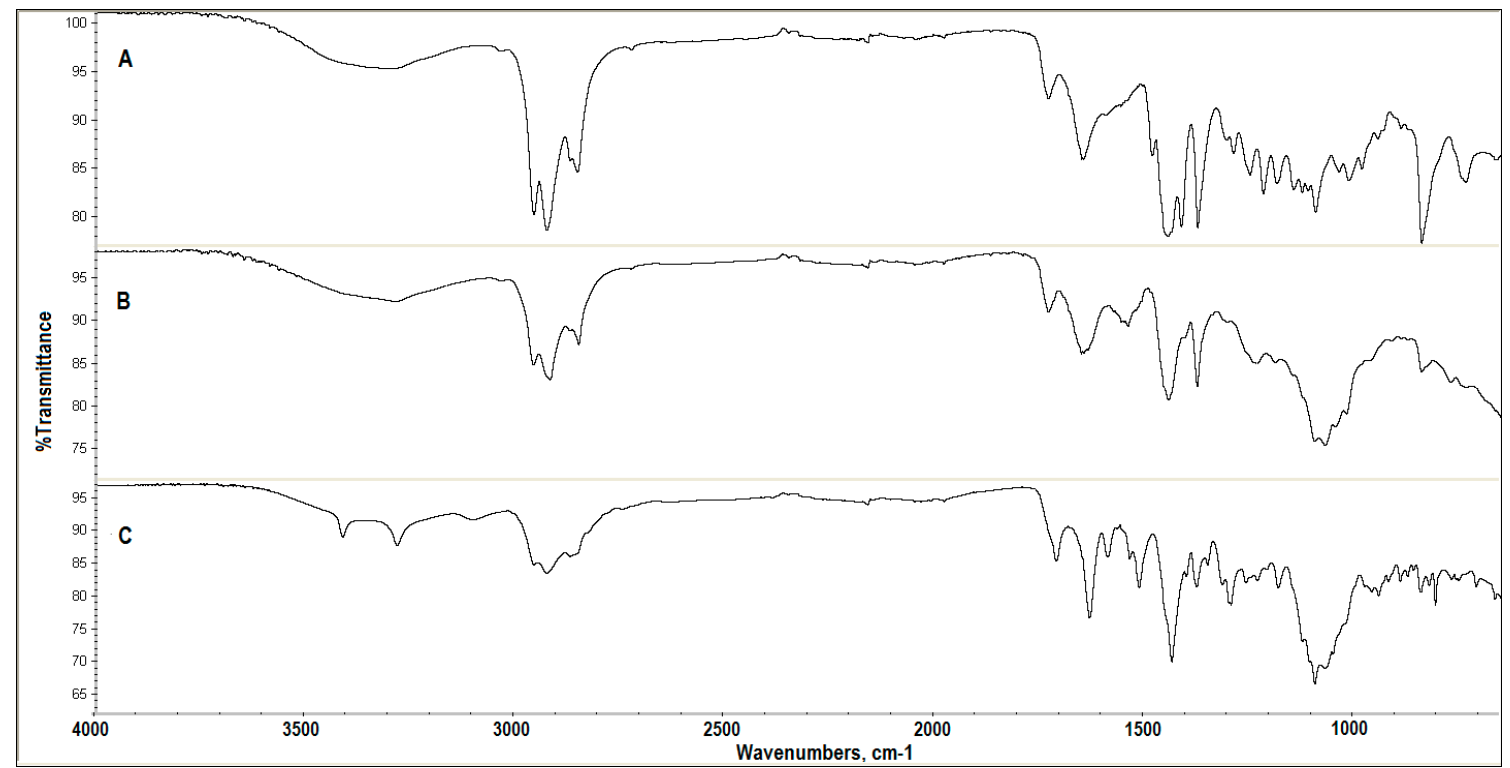

Figure 3. FTIR spectra of catheter surface recorded during a two-stage modification using the SPA-M3 method: the untreated hydrogel catheter (A), the bromine-activated catheter $(\mathbf{B})$, and the SPA-treated catheter $(\mathbf{C})$.

The spectrum of the modified catheter was more like the SPA molecule than the hydrogel latex matrix (Figure 3C). The absorption bands of SPA [16] appeared at $3411 \mathrm{~cm}^{-1}$ and $3285 \mathrm{~cm}^{-1}$ (the N-H asymmetrical and symmetrical stretching), $1636 \mathrm{~cm}^{-1}$ (the $\mathrm{C}=\mathrm{O}$ stretching), $1536-1510 \mathrm{~cm}^{-1}$ (the $\mathrm{C}=\mathrm{C}$ stretching of the aromatic ring), $1437 \mathrm{~cm}^{-1}$ (the $\mathrm{C}-\mathrm{H}$ asymmetrical bending), and in the range of $1293-1095 \mathrm{~cm}^{-1}$ (the stretching vibrations of the C-N, Ar-F, C-O bonds) (Table 3).

Table 3. Summary of the FTIR analysis of the SPA-modified catheter following the SPA-M3 method.

\begin{tabular}{cc}
\hline Prominent Peaks of SPA & Prominent Peaks of SPA-Modified Catheter \\
\hline$v(\mathrm{~N}-\mathrm{H}): 3460 \mathrm{~cm}^{-1}$ and $3336 \mathrm{~cm}^{-1}$ & $v(\mathrm{~N}-\mathrm{H}): \sim 3411 \mathrm{~cm}^{-1}$ and $3285 \mathrm{~cm}^{-1}$ \\
$v(\mathrm{C}=\mathrm{O}$ in $\mathrm{COOH}): 1713 \mathrm{~cm}^{-1}$ & $v(\mathrm{C}=\mathrm{O}$ in $\mathrm{COOH}): \sim 1709 \mathrm{~cm}^{-1}$ \\
$v(\mathrm{C}=\mathrm{O}): 1639 \mathrm{~cm}^{-1}$ & $v(\mathrm{C}=\mathrm{O}): \sim 1636 \mathrm{~cm}^{-1}$ \\
$v(\mathrm{C}=\mathrm{C}$ in $\mathrm{Ar})$ with $\delta(\mathrm{N}-\mathrm{H}): 1585-1495 \mathrm{~cm}^{-1}$ & $v(\mathrm{C}=\mathrm{C}$ in $\mathrm{Ar})$ with $\delta(\mathrm{N}-\mathrm{H}): \sim 1536-1510 \mathrm{~cm}^{-1}$ \\
$\delta(\mathrm{C}-\mathrm{H}$ in $-\mathrm{CH} 2-): 1435 \mathrm{~cm}^{-1}$ & $\delta(\mathrm{C}-\mathrm{H}$ in $-\mathrm{CH} 2-): \sim 1437 \mathrm{~cm}^{-1}$ \\
$v(\mathrm{C}-\mathrm{O}$ in $\mathrm{COOH}): 1290 \mathrm{~cm}^{-1}$ & $v(\mathrm{C}-\mathrm{O}$ in COOH $): \sim 1293 \mathrm{~cm}^{-1}$ \\
\hline
\end{tabular}

\subsection{Analysis of the Polyurethane and Silicone SPA-Modified Catheter Following the SPA-M3 Method}

In order to show the universality of this procedure, the SPA-M3 method was also used for functionalizing the other catheter matrices (i.e., polyurethane or silicone). The immobilization of SPA in the polyurethane and silicone catheter was performed with satisfactory results.

Comparison of the polyurethane catheter before and after immobilization of SPA (Figures 3B and $4 \mathrm{~A}$ ) clearly demonstrated the changes in the catheter matrix. The FTIR spectrum of the modified catheter definitely resembled the spectrum of SPA [16].

The appearance of the absorption peaks at $3418 \mathrm{~cm}^{-1}$ and $3285 \mathrm{~cm}^{-1}$ (the $\mathrm{N}-\mathrm{H}$ stretching), $1632 \mathrm{~cm}^{-1}$ (the $\mathrm{C}=\mathrm{O}$ stretching), $1510 \mathrm{~cm}^{-1}$ (the $\mathrm{C}=\mathrm{C}$ stretching of the aromatic ring), $1435 \mathrm{~cm}^{-1}$ 
(the C-H asymmetrical bending), and in the range of $1300-1000 \mathrm{~cm}^{-1}$ (the stretching vibrations of the $\mathrm{C}-\mathrm{N}, \mathrm{Ar}-\mathrm{F}, \mathrm{C}-\mathrm{O}$ bonds) confirmed the presence of SPA.

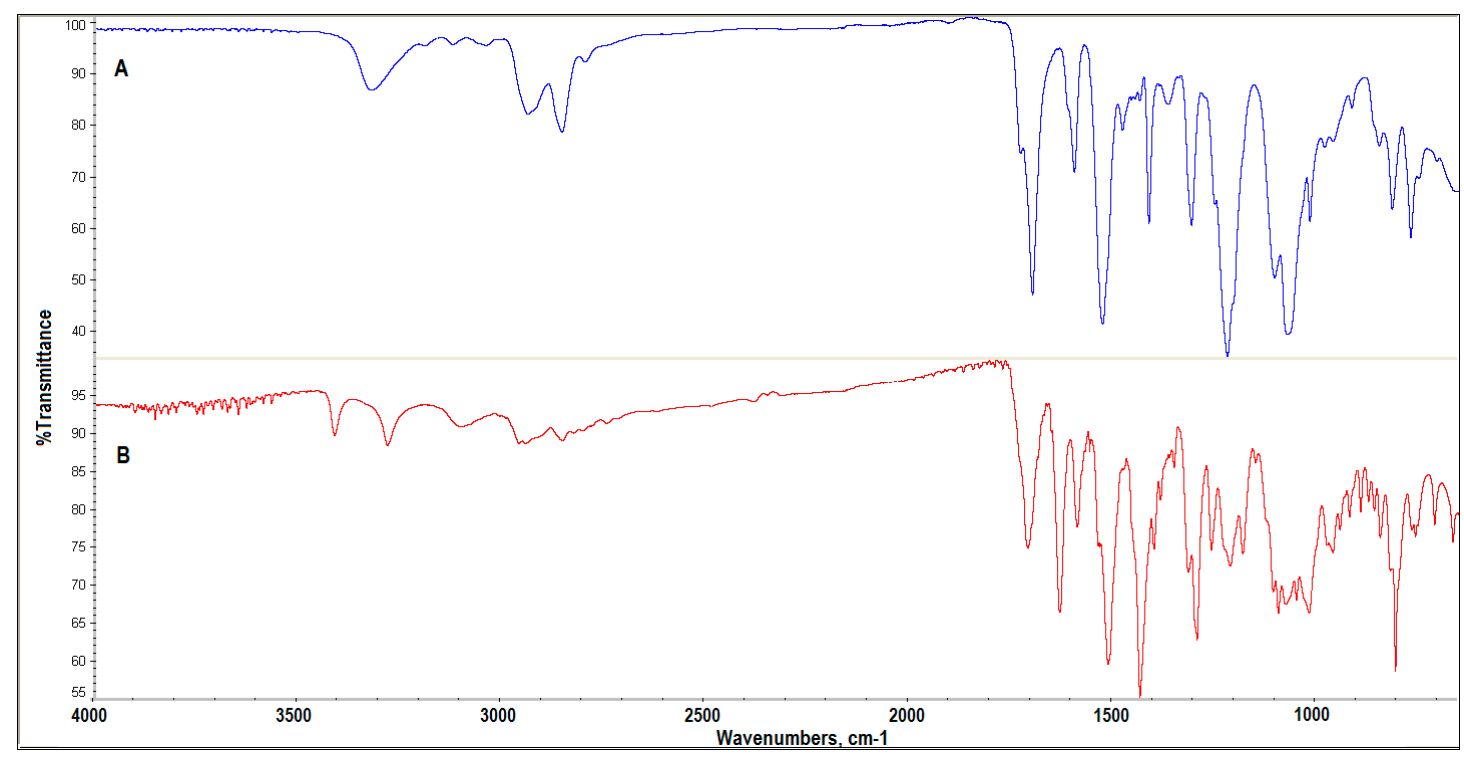

Figure 4. Comparison of the polyurethane catheter before (A) and after (B) immobilization of SPA.

Silicone has a relatively simple infrared spectrum, which is associated with its uncomplicated structure (organosilicon polymer). Silicone exhibits a typical distribution of the absorption bands for this type of material, located in the zone below $1300 \mathrm{~cm}^{-1}$. The peaks in this region corresponded to the absorptions resulting from the antisymmetric and symmetric stretching vibrations of the oxygen atom in the $\mathrm{Si}-\mathrm{O}-\mathrm{Si}$ group [24] as well as the stretching vibrations of the carbon-silicon bond (C-Si) present in all organosilicon compounds. Another absorption band at $2954 \mathrm{~cm}^{-1} \mathrm{can}$ be attributed to the $\mathrm{C}-\mathrm{H}$ stretching vibrations of the methyl groups in the silicone structure.

The presented spectra (Figure 5) show changes of the silicone after immobilization of SPA. Numerous absorption bands characteristic of SPA, similar to the polyurethane matrix, confirmed incorporation of SPA to the silicone matrix. More intense bands were the effect of using a higher activator concentration ( $0.3 \%$ and $1.0 \%$ bromine solution). It was also found that with the increased concentration of bromine, the structure of the silicone catheter became more fragile.

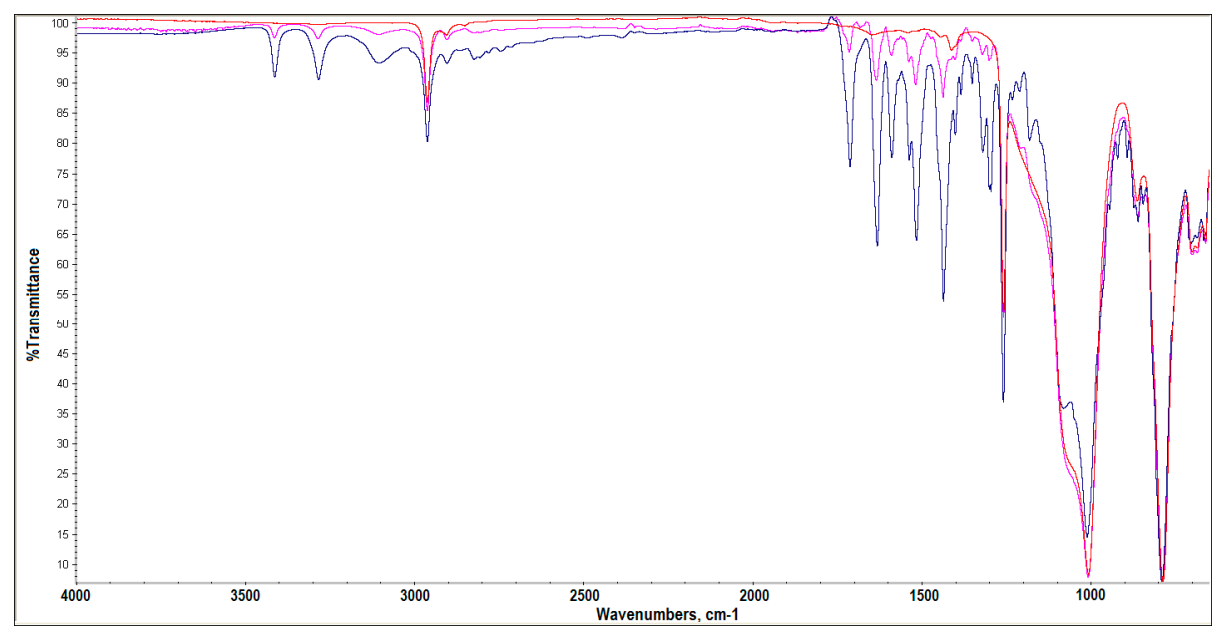

Figure 5. Comparison of the silicone catheter before (red curve) and after (pink and blue curves) immobilization of SPA; the activation with bromine at concentration $0.3 \%$ (pink curve) and $1 \%$ (blue curve). 


\subsection{Analysis of the CIP-Modified Catheter with the Use of the CIP-M1 Method}

The FTIR spectrum of ciprofloxacin shows many absorption bands (Figure 6). The most characteristic bands can be assigned to the $\mathrm{O}-\mathrm{H}$ stretching in $\mathrm{COOH}$ at $3530-3373 \mathrm{~cm}^{-1}$, the N-H stretching of the ionized amine $\left(>\mathrm{NH}_{2}{ }^{+}\right)$at $2689-2463 \mathrm{~cm}^{-1}$, the $\mathrm{C}=\mathrm{O}$ stretching in $\mathrm{COOH}$ and 4-quinolone ring at $1703 \mathrm{~cm}^{-1}$ and $1623 \mathrm{~cm}^{-1}$, respectively, the $\mathrm{C}=\mathrm{C}$ stretching in aromatic ring at $1588-1495 \mathrm{~cm}^{-1}$, the $\mathrm{C}-\mathrm{H}$ bending at $1449 \mathrm{~cm}^{-1}$, the $\mathrm{C}-\mathrm{N}$ stretching at $1384 \mathrm{~cm}^{-1}$, the $\mathrm{C}-\mathrm{O}$ stretching in $\mathrm{COOH}$ at $1267 \mathrm{~cm}^{-1}$, and the C-F stretching vibrations in the range of $1250-1100 \mathrm{~cm}^{-1}$.

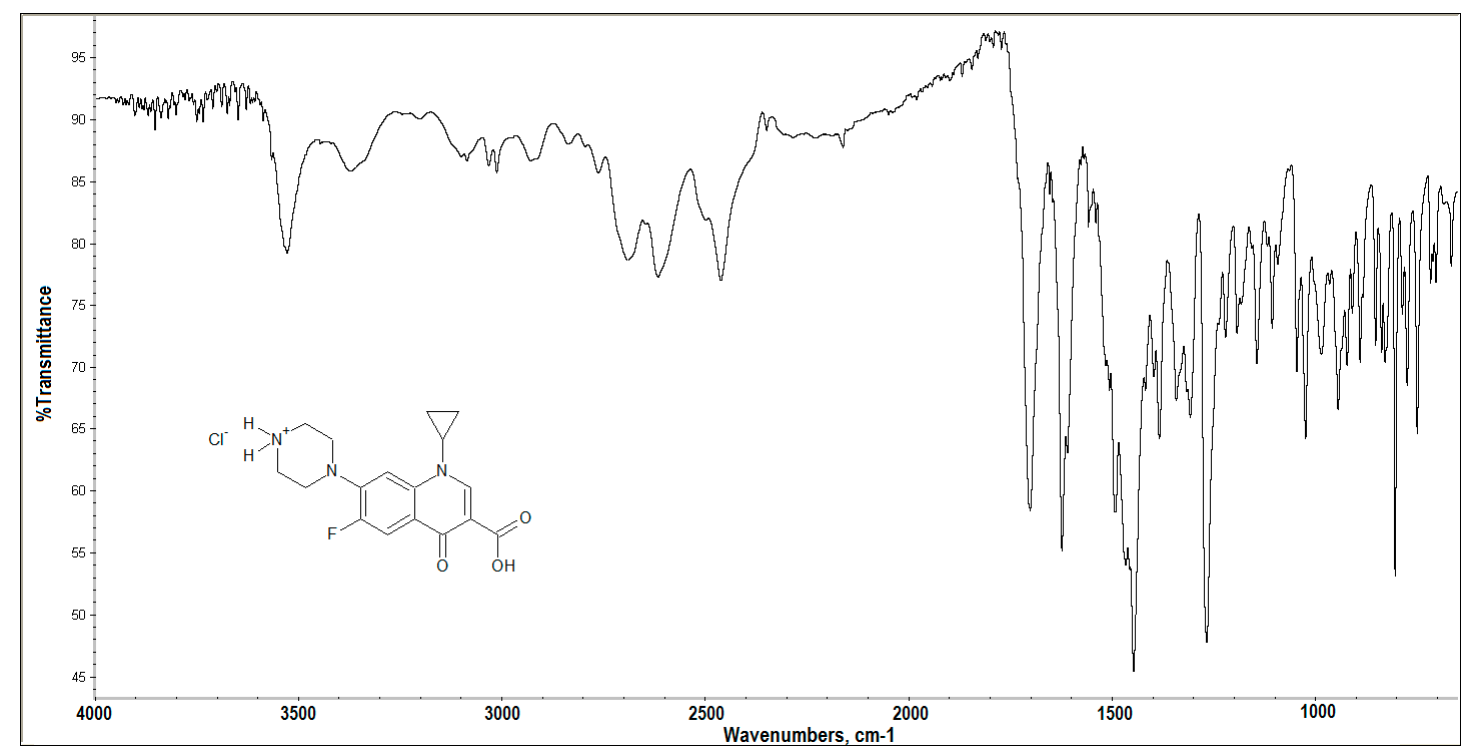

Figure 6. FTIR spectrum of ciprofloxacin hydrochloride monohydrate.

The changes occurring in the course of the first (CHT-treated catheter) and second (GLU-activated catheter) stage of the modification (Figure $7 \mathrm{~B}$ ) were the same as those observed during the formation of the crosslinking chitosan (Figure 1B): the double imine bond $(\mathrm{N}=\mathrm{C})$ at $1644 \mathrm{~cm}^{-1}$ and the ethylenic double bond $(\mathrm{C}=\mathrm{C})$ at $1551 \mathrm{~cm}^{-1}$.

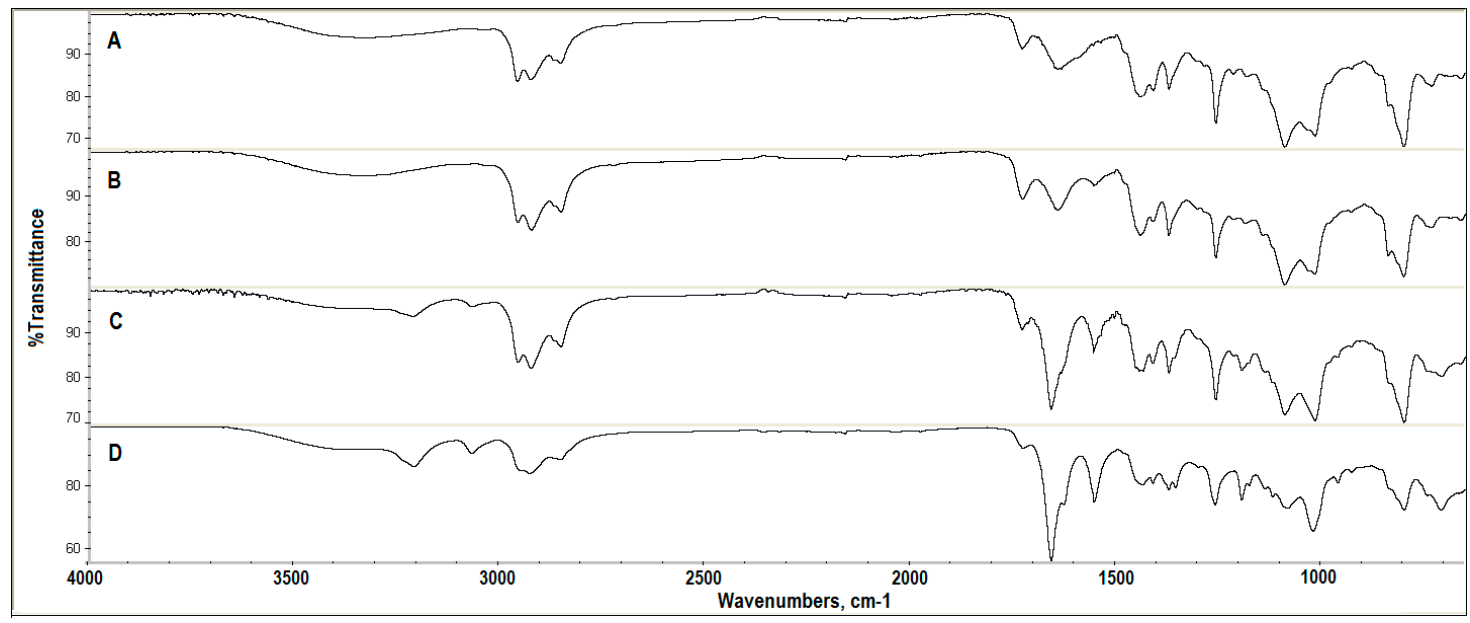

Figure 7. FTIR spectra of the siliconized latex catheter recorded during multi-stage modification using the CIP-M1 method: the untreated catheter (A), CHT-treated, GLU-activated catheter (B), CHT-treated, GLU-ADH activated catheter (C), and CIP-treated catheter (D).

In the next stage, the cross-linked chitosan was functionalized with adipic acid dihydrazide as the second linker, $\mathrm{NH}_{2} \mathrm{NH}-\mathrm{CO}-\left(\mathrm{CH}_{2}\right)_{3}-\mathrm{CO}-\mathrm{NHNH}_{2}$ [25]. 
The appearance of the strong peak (Figure 7C) at $1660 \mathrm{~cm}^{-1}$ belonging to the stretching vibrations of the $\mathrm{N}=\mathrm{C}$ bond proves that $\mathrm{ADH}$ binds covalently with the cross-linked chitosan in order to introduce the amine groups whose peaks occur at $3215 \mathrm{~cm}^{-1}$ and $3068 \mathrm{~cm}^{-1}$. Moreover, the new amido bonds' characteristic peaks at $1699 \mathrm{~cm}^{-1}$ and $1560 \mathrm{~cm}^{-1}$, corresponding to the stretching vibrations of $\mathrm{C}=\mathrm{O}$ and the bending vibrations of $\mathrm{N}-\mathrm{H}$, indicate the presence of $\mathrm{ADH}$ in the modified catheter.

In the last stage, the attachment of CIP to the GLU-ADH activated catheter was observed (Figure 7D). In the CIP-treated catheter spectrum, the $\mathrm{C}=\mathrm{N}$ stretching band was intensified in comparison to the GLU-ADH activated catheter spectrum, which was indicative of the interaction between CIP and ADH. Moreover, the stronger peaks at $3300-3000 \mathrm{~cm}^{-1}$ and the broader band at $3000-2800 \mathrm{~cm}^{-1}$ can suggest that there are more $\mathrm{N}-\mathrm{H}$ and $\mathrm{CH}_{2}$ groups in the CIP-treated catheter than in the GLU-ADH activated catheter, which may indicate the introduction of CIP. Furthermore, the shape change of the bands in the region of $1600-1000 \mathrm{~cm}^{-1}$ and the appearance of new peaks may also be suggestive of the presence of CIP (Table 4).

Table 4. Summary of FTIR analysis of the CIP-modified catheter following the CIP-M1 method.

\begin{tabular}{cc}
\hline Prominent Peaks of CIP & Prominent Peaks of CIP-Modified Catheter \\
\hline$v\left(\mathrm{~N}-\mathrm{H}\right.$ in $\left.>\mathrm{NH}_{2}{ }^{+}\right): 2689-2463 \mathrm{~cm}^{-1}$ & $v\left(\mathrm{~N}-\mathrm{H}\right.$ in $\left.>\mathrm{NH}_{2}^{+}\right):$absence \\
$v(\mathrm{C}=\mathrm{O}): 1623 \mathrm{~cm}^{-1}$ & $v(\mathrm{C}=\mathrm{N}): \sim 1660 \mathrm{~cm}^{-1}$ \\
$v(\mathrm{C}=\mathrm{C}$ in $\mathrm{Ar}): 1588-1495 \mathrm{~cm}^{-1}$ & $v(\mathrm{C}=\mathrm{C}$ in $\mathrm{Ar}): \sim 1555 \mathrm{~cm}^{-1}$ \\
$\delta(\mathrm{C}-\mathrm{H}$ in $-\mathrm{CH} 2-): 1449 \mathrm{~cm}^{-1}$ & $\delta(\mathrm{C}-\mathrm{H}$ in $-\mathrm{CH} 2-): 1445 \mathrm{~cm}^{-1}$ \\
$v(\mathrm{C}-\mathrm{O}$ in $\mathrm{COOH}): 1267 \mathrm{~cm}^{-1}$ & $v(\mathrm{C}-\mathrm{O}$ in $\mathrm{COOH}): \sim 1267 \mathrm{~cm}^{-1}$ \\
\hline
\end{tabular}

A qualitative FTIR study of catheters treated with increasing concentrations of drugs during modification with use of all immobilization methods (SPA-M1, M2, M3, and CIP-M1) was performed to better assess the drug-specific absorption bands. The changes in the shape of the characteristic absorption bands in a series of the studied samples confirmed the presence of SPA and CIP in the catheter matrix.

The representative FTIR spectra in Figure 8 demonstrate the increasing intensity of SPA-characteristic bands as a consequence of the increasing amounts of SPA embedded in the catheter matrix. For this assessment, the N-H stretching of the SPA amine group at 3500-3295 $\mathrm{cm}^{-1}$, and the $\mathrm{C}=\mathrm{O}$ stretching vibrations at $1639 \mathrm{~cm}^{-1}$ derived from $\mathrm{COOH}$ group are particularly important. The presented FTIR spectra illustrate the successful binding of the drug with the catheter matrix.

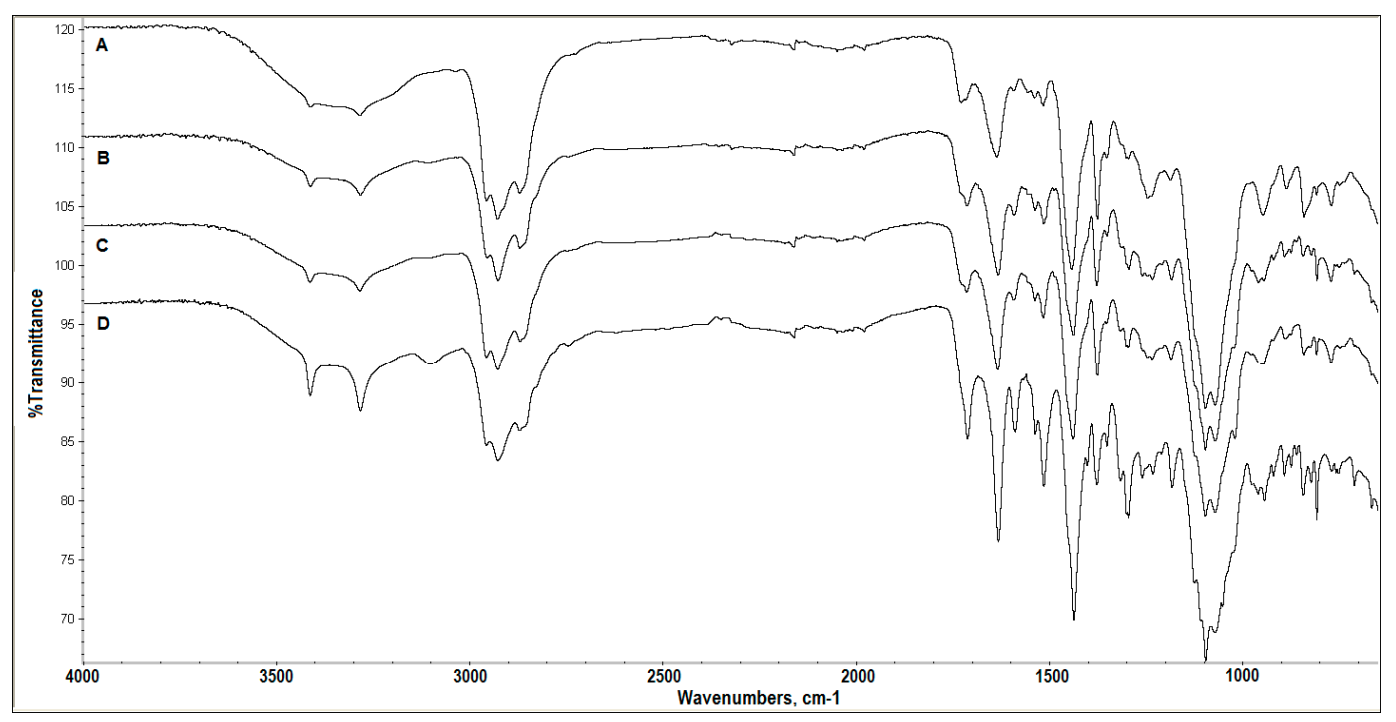

Figure 8. Typical FTIR spectra of the catheter with SPA immobilized from solutions with increasing SPA concentrations: 0.1 (A), 0.5 (B), 1.0 (C), and 2.0 (D) mg/mL (SPA-M3 method). 


\section{Discussion}

Urinary tract infections are the most commonly occurring nosocomial infections in intensive care units. Most of these infections are associated with the presence of catheters in the urinary tract [1-3]. Two main problems that affect urinary catheters and make it more difficult to treat catheter-associated urinary tract infections are biofilm formation and encrustation. The biofilm bacteria can move to the kidneys, causing life-threatening complications. On the other hand, the incrustation/mineralization of the catheter with calcium and phosphorus salts promotes bacterial adhesion [26-28]. A common treatment for urinary infections is the use of antimicrobials in urinary catheters, which can reduce or eliminate colonization of bacteria and stop the biofilm formation.

In order to achieve an antifouling and antimicrobial coating, polymers are mostly impregnated with many types of antimicrobials with the participation of various methods of immobilization, which include: a procedure in which the active agents are covalently bound to the polymer (grafting); physical adsorption in which the active agents are non-covalently coupled to the polymer by hydrogen, ionic, or steric interactions; surface-initiated immobilization in which the synthesis of the antimicrobial on the polymer surface occurs due to the use of a covalently bonded initiator; and immobilization in which the synthesis of the active agent occurs within the substrate when it is formed [2].

Coating urinary catheters with the polymer hydrogel, often impregnated with antimicrobials, is a popular proposition in order to reduce diminishing the adhesion of microbes. In such a preventive strategy, polymers such as polyvinylpyrrolidone, chitosan [29,30], curdlan [31], heparin [32], mucin-the main component of the mucosa with anti-adhesive properties [33] —have been recommended. It was shown that the biomaterial coated with polymer was colonized by bacteria to a lesser extent than an unaltered one and was often less prone to incrustation, which is especially important for the biomaterials used in urology [28,32].

The above-mentioned studies were the motivation for coating urological catheters with the chitosan hydrogel and conducting further modifications with an intention to achieve effective, multidirectional, and long-term antibacterial protection. The following process of functionalization of the chitosan hydrogel consisted in its activation via crosslinking with the use of glutaraldehyde (Figure 1B) or glutaraldehyde and adipic acid dihydrazide (Figure 7B,C). Finally, fluoroquinolone- the main component of the antibacterial protection-was bound with the activated catheter, the first strategy of antibacterial modification (Figures 1C and 7D). It is known that glutaraldehyde is one of the crosslinking agents that is potentially cytotoxic. However, the reactivity of glutaraldehyde with amine and other functional groups of proteins and enzymes has led to its widespread use as a crosslinking agent for proteins and other compounds. The studies suggest that the toxic effect of glutaraldehyde can be quenched by glutamic acid [34] or other cell-friendly amine compounds. Our previous study indicates that the chitosan coat crosslinked with glutaraldehyde and then treated with tosufloxacin provides good protection against the cytotoxic effect of the silicone latex material; it probably limits leaching of harmful agents [35]. Moreover, recent studies have revealed that the glutaraldehyde cross-linked chitosan exhibits an antibacterial activity. This property appears to be desirable in the case of creating antibacterial coatings [36].

The second strategy of the antibacterial modification consisted in the functionalization of the ready-made hydrogel catheters by the hydrogel activation with iodine (Figure $2 \mathrm{~B}$ ) or bromine (Figure $3 \mathrm{~B}$ ), followed by incorporation of the antimicrobials into the catheter matrix (Figures $2 \mathrm{C}$ and $3 \mathrm{C}$, respectively).

Modification of the surface with the participation of sparfloxacin was conducted according to the first and second strategy by applying three different immobilization methods marked as SPA-M1, SPA-M2, and SPA-M3. In the case of the SPA-M1 method, the catheter's surface was coated with the chitosan hydrogel, activated with GLU (crosslinking), and treated with SPA, according to the patented procedure [17]. In the case of the SPA-M2 and the SPA-M3 methods, the ready-made hydrogel catheters were activated with iodine or bromine, respectively, and then treated with SPA. The SPA-M3 method was also used for functionalizing the polyurethane and silicone catheters in order to show the 
universality of this procedure. The immobilization of SPA in the polyurethane and silicone catheter produced satisfactory results (Figures 4 and 5 , respectively). However, the structure of the silicone catheter underwent gradual destruction under the influence of bromine. Therefore, this way of modification cannot be proposed in the case of silicone materials.

Modifications with the application of ciprofloxacin were performed according to the first strategy (Figure 7) and with the use of the immobilization method marked as CIP-M1. The catheter surface was coated with the chitosan hydrogel, activated with GLU and adipic acid dihydrazide, and finally treated with CIP according to the patented procedure [17].

The manner of binding CIP and SPA with the catheter matrix was assessed on the basis of the recorded FTIR spectra after each stage of modification. Frequent recording of the spectrum of the tested material after each subsequent stage of modification enables finding even the smallest changes. It is not necessary to use the spectrum library, because during the spectrum analysis, it is easy to deduce which functional group in the drug molecule or polymer took part in the interaction [16,18]. Analysis of the FTIR spectra of pure substances CIP (Figure 6) and SPA [17] was used for identification of the most characteristic absorption bands corresponding to the vibrations of the respective functional groups in the molecules of both compounds. It was proven that CIP and SPA immobilized, according to the first method (CIP-M1, SPA-M1), bind with the catheter matrix by covalent bonds, probably in a mixed covalent-noncovalent manner. The increase in the intensity of absorption bands at $1630 \mathrm{~cm}^{-1}$ (SPA) and $1660 \mathrm{~cm}^{-1}$ (CIP), which corresponds to the stretching vibrations of the imine bond $(\mathrm{C}=\mathrm{N})$ formed between the amine or carbonyl groups of the molecules of drugs and the modified chitosan hydrogel (Figures 1C and 7D) may be evidence of covalent interactions. The mixed binding of the drugs can confirm the inhibition zones of bacterial growth under and around the catheter in the microbiological test: the zone inhibition test against the selected Gram-positive and Gram-negative bacteria. Similar effects were observed previously (i.e., during immobilization of SPA on the catheter coated with heparin [37]).

In the case of the immobilization of SPA according to the second and third method (SPA-M2, SPA-M3), the recorded FTIR spectra showed distinct bands deriving from the moieties that are characteristic of the SPA molecule, especially the bands at 3500-3280, corresponding to the SPA primary amine group. The presence of a free amine group indicates that the drug's bond is noncovalent (Figures $2 \mathrm{C}$ and $3 \mathrm{C}$ ).

On the basis of the intensification of the absorption bands belonging to the vibrations of the bonds of the functional groups, it was concluded that the increase in the drug concentration in the solutions used for immobilization resulted in the increase in the amounts of drugs found in the catheter matrix (Figure 8).

In the present study, the HPLC method [38] was adopted for assessing the degree of CIP/SPA binding with the modified latex catheter. The drugs were determined in the solution before and after immobilization, and their concentrations were calculated from the equations of regression: $y=131,196.3 x+21,192.7$ for CIP and $y=96,999.7 x+10,571.1$ for SPA.

The results show that CIP bonded in $15-20 \%$ (1.5-2.3 mg per $1 \mathrm{~g}$ catheter), whereas SPA in $26-47 \%$ (2.9-5.2 mg per $1 \mathrm{~g}$ catheter) when the CIP-M1 and SPA-M1 methods were used, respectively. When the SPA-M2 and SPA-M3 methods were in use, $25-32 \%$ of SPA (2.8-3.6 mg per $1 \mathrm{~g}$ catheter) and $48-60 \%$ of SPA (5.4-6.7 mg per g catheter), respectively, were immobilized in the catheter matrix.

In order to assess the durability of the drug binding, the release profiles of both drugs from the modified latex catheter were determined. It was found that the drugs immobilized with the use of all methods were released gradually in small doses, providing long-term antibacterial protection of the catheter as well as the environment around it. Amounts of about $0.6 \%$ of CIP and $0.7 \%$ of SPA for the M1 method, $1.9 \%$ of SPA for the M2 method, and 1.3\% of SPA for the M3 method were released by shaking the SPA/CIP loaded catheter samples in $10 \mathrm{~mL}$ of phosphate buffer at $\mathrm{pH} 5.5$ for $30 \mathrm{~min}$ daily at $37^{\circ} \mathrm{C}$ for a month. In the case of the M1 method, the drug release below $1 \%$ within one 
month confirmed a considerable stability of the $\mathrm{C}=\mathrm{N}$ bonds and thus the stability of coatings based on chitosan crosslinked with glutaraldehyde.

\section{Conclusions}

Since the ideal antibacterial material has not yet been found, there is still a need to look for new ways of the prevention of catheter-associated urinary tract infections. New antibacterial coatings and materials must be thoroughly tested using reliable characterization methods to achieve the highest antimicrobial efficacy and safety.

The findings presented in this paper allow for the conclusion that the new antimicrobial coatings, obtained with the participation of fluoroquinolone antibiotics in an uncomplicated way, are able to protect the urinary catheters against bacterial infections during catheterization. The formation methods of antimicrobial catheter coatings through the covalent and noncovalent immobilization of fluoroquinolones were developed. In the case of covalent immobilization, it is predicted that the deposited coatings present a crosslinked chitosan thin film with the bonded drug, which preserves the antibacterial properties. It is also estimated that in the case of a noncovalent binding, the drug becomes trapped in the micro pores of the polymer matrix formed while being treated with bromine/iodine. The fluoroquinolones were successfully incorporated into the catheter matrix, which was confirmed by the FTIR analysis. Incorporation of the drug following activation with bromine is a suitable method of modifying latex and polyurethane-based catheters, but in the case of silicone, its structure is damaged. A dissolution study confirmed the stability of the drug binding to the matrix. A relatively durable binding of the drug enables long-term protection of the catheter against infection. In contrast, the low dose release protects the environment around the catheter. However, in order to evaluate their potential application in practice, further research should focus on the confirmation of their mechanical properties, efficacy, and safety.

Funding: This research was funded by the Polish Ministry of Scientific Research and Information Technology, grant number N N405 385037.

Acknowledgments: The author thanks Renata Steliga and Jakub Krol, students at the Chair and Department of Medicinal Chemistry, the Medical University of Lublin, for their assistance in preparing the modified catheter samples.

Conflicts of Interest: The author declares no conflict of interest.

\section{References}

1. Anjum, S.; Singh, S.; Benedicte, L.; Roger, P.; Panigrahi, M.; Gupta, B. Biomodification Strategies for the Development of Antimicrobial Urinary Catheters: Overview and Advances. Glob. Chall. 2018, 2, 1700068. [CrossRef]

2. Singha, P.; Locklin, J.; Handa, H. A Review of the Recent Advances in Antimicrobial Coatings for Urinary Catheters. Acta Biomater. 2017, 50, 20-40. [CrossRef]

3. Andersen, M.J.; Flores-Mireles, A.L. Urinary Catheter Coating Modifications: The Race against Catheter-Associated Infections. Coatings 2020, 10, 23. [CrossRef]

4. Sekiguchi, Y.; Yao, Y.; Ohko, Y.; Tanaka, K.; Ishido, T.; Fujishima, A.; Kubota, Y. Self-sterilizing catheters with titanium dioxide photocatalyst thin films for clean intermittent catheterization: Basis and study of clinical use. Int. J. Urol. 2007, 14, 426-430. [CrossRef] [PubMed]

5. Yao, Y.; Ohko, Y.; Sekiguchi, Y.; Fujishima, A.; Kubota, Y. Self-sterilization using silicone catheters coated with Ag and $\mathrm{TiO}_{2}$ nanocomposite thin film. J. Biomed. Mater. Res. B Appl. Biomater. 2008, 85, 453-460. [CrossRef] [PubMed]

6. Roe, D.; Karandikar, B.; Bonn-Savage, N.; Gibbins, B.; Roullet, J.B. Antimicrobial surface functionalization of plastic catheters by silver nanoparticles. J. Antimicrob. Chemother. 2008, 61, 869-876. [CrossRef]

7. Regev-Shoshani, G.; Ko, M.; Av-Gay, Y. Slow release of nitric oxide from charged catheters and its effect formation on biofilm formation by Escherichia coli. Antimicrob. Agents Chemother. 2010, 54, 273-279. [CrossRef] 
8. Jones, G.L.; Muller, C.T.; O' Reilly, M.; Stickler, D.J. Effect of triclosan on the development of bacterial biofilms by urinary tract pathogens on urinary catheters. J. Antimicrob. Chemother. 2006, 57, 266-272. [CrossRef]

9. Gaonkar, T.A.; Caraos, L.; Modak, S. Efficacy of a silicone urinary catheter impregnated with chlorhexidine and triclosan against colonization with Proteus mirabilis and other uropathogenes. Infect. Control Hosp. Epidemiol. 2007, 28, 596-598. [CrossRef]

10. Cormio, L.; La Forgia, P.; La Forgia, D.; Siitonen, A.; Ruutu, M. Bacterial adhesion to urethral catheters: Role of coating materials and immersion in antibiotic solution. Eur. Urol. Urol. 2001, 40, 354-359. [CrossRef]

11. Park, J.H.; Cho, Y.W.; Cho, Y.; Choi, J.M.; Shin, J.S.; Bae, Y.H.; Chung, H.; Jeong, S.Y.; Kwon, I.C. Norfloxacin-Releasing urethral catheter for long-term catheterization. J. Biomater. Sci. Polym. Edn 2003, 14, 951-962. [CrossRef]

12. Johnson, J.R.; Johnston, B.; Kuskowski, M.A. In vitro comparison of nitrofurazone- and silver alloy-coated foley catheters for contact-dependent and diffusible inhibition of urinary tract infection-associated microorganisms. Antimicrob. Agents Chemother. 2012, 56, 4969-4972. [CrossRef] [PubMed]

13. Thompson, V.C.; Adamson, P.J.; Dilag, J.; Liyanage, D.B.U.; Srikantharajah, K.; Blok, A.; Ellis, A.V.; Gordonb, D.L.; Koper, I. Biocompatible anti-microbial coatings for urinary catheters. RSC Adv. 2016, 6, 53303-53309. [CrossRef]

14. Kondyurina, I.; Nechitailo, G.S.; Svistkov, A.L.; Kondyurin, A.; Bilek, M. Urinary catheter with polyurethane coating modified by ion implantation. Nucl. Instrum. Methods Phys. Res. B 2015, 342, 39-46. [CrossRef]

15. Floroian, L.; Ristoscu, C.; Mihailescu, N.; Negut, I.; Badea, M.; Ursutiu, D.; Chifiriuc, M.C.; Urzica, I.; Dyia, H.M.; Bleotu, C.; et al. Functionalized Antimicrobial Composite Thin Films Printing for Stainless Steel Implant Coatings. Molecules 2016, 21, 740. [CrossRef]

16. Kowalczuk, D.; Pitucha, M. Application of FTIR Method for the Assessment of Immobilization of Active Substances in the Matrix of Biomedical Materials. Materials 2019, 12, 2972. [CrossRef]

17. Kowalczuk, D.; Ginalska, G. The Method for Preparing the Antimicrobial Biomaterial via Immobilization of the Antibacterial Substance on its Surface. Medical University of Lublin, Poland. Patent PL 214742 B1, 30 September 2013.

18. Xiao, X.; Xu, R. Preparation and surface properties of core-shell polyacrylate latex containing fluorine and silicon in the shell. J. Appl. Polym. Sci. 2011, 119, 1576-1585. [CrossRef]

19. Monteiro, O.A.C.; Airoldi, C. Some studies of crosslinking chitosan-glutaraldehyde interaction in a homogeneous system. Int. J. Biol. Macromol. 1999, 26, 119-128. [CrossRef]

20. Kil'deeva, N.R.; Perminov, P.A.; Vladimirov, L.V.; Novikov, V.V.; Mikhailov, S.N. Mechanism of the reaction of glutaraldehyde with chitosan. Russ. J. Bioorg. Chem. 2009, 35, 397-407. [CrossRef]

21. Islam, N.; Taha, M.O.; Dmour, I. Degradability of chitosan micro/nanoparticles for pulmonary drug delivery. Heliyon 2019, 5, e01684. [CrossRef]

22. Lawrence, E.L.; Turner, I.G. Materials for urinary catheters: A review of their history and development in the UK. Med. Eng. Phys. 2005, 27, 443-453. [CrossRef]

23. Perova, T.S.; Vij, J.K.; Xu, H. Fourier transform infrared study of poly(2-hydroxyethyl methacrylate) PHEMA. Colloid Polym. Sci. 1997, 275, 323-332. [CrossRef]

24. Abenojar, J.; Martınez, M.A.; Encinas, N.; Velasco, F. Modification of glass surfaces adhesion properties by atmospheric pressure plasma torch. Int. J. Adhes. Adhes. 2013, 44, 1-8. [CrossRef]

25. Zheng, E.; Dang, Q.; Liu, C.; Fan, B.; Yan, J.; Yu, Z.; Zhang, H. Preparation and evaluation of adipic acid dihydrazide cross-linked carboxymethyl chitosan microspheres for copper ion adsorption. Colloids Surf. A Physicochem. Eng. Asp. 2016, 502, 34-43. [CrossRef]

26. Jacobsen, S.M.; Stickler, D.J.; Mobley, H.L.T.; Shirtliff, M.E. Complicated Catheter-Associated Urinary Tract Infections Due to Escherichia coli and Proteus mirabilis. Clin. Microbiol. Rev. 2008, 21, 26-59. [CrossRef] [PubMed]

27. Cicciu, M.; Fiorillo, L.; Herford, A.S.; Crimi, S.; Bianchi, A.; D’Amico, C.; Laino, L.; Cervino, G. Bioactive Titanium Surfaces: Interactions of Eukaryotic and Prokaryotic Cells of Nano Devices Applied to Dental Practice. Biomedicines 2019, 7, 12. [CrossRef] [PubMed]

28. Fiorillo, L.; Cervino, G.; Laino, L.; D’Amico, C.; Mauceri, R.; Tozum, T.F.; Gaeta, M.; Cicciù, M. Porphyromonas gingivalis, Periodontal and Systemic Implications: A Systematic Review. Dent. J. 2019, 7, 114. [CrossRef] 
29. Borowska, M.; Glinka, M.; Filipowicz, N.; Terebieniec, A.; Szarlej, P.; Kot-Wasik, A.; Kucińska-Lipka, J. Polymer biodegradable coatings as active substance release systems for urological applications. Monatsh. Chem. 2019, 150, 1697-1702. [CrossRef]

30. Yang, S.H.; Lee, Y.S.; Lin, F.H.; Yang, J.M.; Chen, K.S. Chitosan/poly(vinyl alcohol) blending hydrogel coating improves the surface characteristics of segmented polyurethane urethral catheters. J. Biomed. Mater. Res. B 2007, 304-313. [CrossRef]

31. Khandwekar, A.P.; Patil, D.P.; Khandwekar, V.; Shouche, Y.S.; Sawant, S.; Doble, M. TecoflexTM functionalization by curdlan and its effect on protein adsorption and bacterial and tissue cell adhesion. J. Mater. Sci. Mater. Med. 2009, 20, 1115-1129. [CrossRef]

32. Tenke, P.; Riedl, C.R.; Jones, G.L.; Williams, G.J.; Stickler, D.; Nagyd, E. Bacterial biofilm formation on urologic devices and heparin coating as preventive strategy. Int. J. Antimicrob. Agents. 2004, 23, S67-S74. [CrossRef] [PubMed]

33. Svensson, O.; Arnebrant, T. Mucin layers and multilayers-Physicochemical properties and applications. Curr. Opin. Colloid Interface Sci. 2010, 15, 395-405. [CrossRef]

34. Gough, J.E.; Scotchford, C.A.; Downes, S. Cytotoxicity of glutaraldehyde crosslinked collagen/poly(vinyl alcohol) films is by the mechanism of apoptosis. J. Biomed. Mater. Res. 2002, 61, 121-130. [CrossRef] [PubMed]

35. Kowalczuk, D.; Przekora, A.; Ginalska, G. Biological safety evaluation of the modified urinary catheter. Mater. Sci. Eng. C 2015, 49, 274-280. [CrossRef]

36. Li, B.; Shan, C.-L.; Zhou, Q.; Fang, Y.; Wang, Y.-L.; Xu, F.; Han, L.-R.; Ibrahim, M.; Guo, L.-B.; Xie, G.-L.; et al. Synthesis, Characterization, and Antibacterial Activity of Cross-Linked Chitosan-Glutaraldehyde. Mar. Drugs 2013, 11, 1534-1552. [CrossRef]

37. Kowalczuk, D.; Ginalska, G.; Golus, J. Characterization of the developed antimicrobial urological catheters. Int. J. Pharm. 2010, 402, 175-183. [CrossRef]

38. Kowalczuk, D.; Ginalska, G.; Gowin, E. Development and comparison of HPLC method with fluorescence and spectrophotometric detections for determination of sparfloxacin. Ann. UMCS Sect. DDD 2011, 24, 163-169.

(C) 2020 by the author. Licensee MDPI, Basel, Switzerland. This article is an open access article distributed under the terms and conditions of the Creative Commons Attribution (CC BY) license (http://creativecommons.org/licenses/by/4.0/). 